UDC 04.316:303; 316:001.8

LBC 60.5

\title{
THE QUALITY OF SERVICE PROVISION BY SPECIAL LIBRARIES FOR THE VISUALLY CHALLENGED IN REGIONAL SCALE
}

\author{
Tatyana V. Andriyanova \\ Kursk State University, Kursk, Russian Federation
}

\begin{abstract}
The study deals with the regional scale of the quality of services provided by special libraries for the visually challenged. Satisfaction with the quality of services provided by special institutions for persons with disabilities, as exemplified by the libraries for the visually challenged, helps to understand and identify current barriers. These barriers include physical ones of the infrastructure of cultural institutions, and other types financial, social, educational, negatively affecting the quality of services.

In the context of this issue the author considers it necessary to address the legal component of the service provision to persons with disabilities by cultural institutions. The main documents starting with the Declaration of human rights (1948) emphasize the need to create a type of social inclusion of persons with disabilities in every society and that would allow them to fully realize their civil rights. In practice, every person with disabilities encounters obstacles along the way. This also applies to special libraries for the visually challenged, who having sufficient experience in this field, can only become a division of public libraries. New Model standard of public libraries charges them to serve visually challenged users. This, in turn, can have a negative impact on the quality of services provided, as public libraries do not have appropriate capabilities, technical and human resources. The relevance of measuring the quality of services of special libraries for the visually challenged is due to their high importance as a social institution with universal opportunities to meet the basic needs of the visually impaired. The results of the study suggest a high satisfaction of visitors of special libraries for the visually challenged with the quality of services, which is one of the main criteria in assessing the work of cultural institutions of this type. Reaching the conclusions on the basis of the above-stated the author points out the need to improve the methodology for measuring the quality of services provided by special libraries for the visually challenged and the possibility for further study of this issue.

Key words: the quality of services, independent evaluation of the quality of services, satisfaction with the quality, special libraries for the visually challenged, area studies.
\end{abstract}

УДК 04.316:303; 316:001.8

ББК 60.5

\section{КАЧЕСТВО ОКАЗАНИЯ УСЛУГ СПЕЦИАЛЬНЫМИ БИБЛИОТЕКАМИ ДЛЯ СЛЕПЫХ В РЕГИОНАЛЬНОМ ИЗМЕРЕНИИ}

\author{
Татьяна Владимировна Андриянова
}

Курский государственный университет, г. Курск, Российская Федерация 


\section{СОЦИОЛОГИЯ И СОЦИАЛЬНЫЕ ТЕХНОЛОГИИ}

вать свои гражданские права. На практике каждый человек с ограниченными возможностями здоровья встречает препятствия на этом пути. Это касается и специальных библиотек для слепых, которые, имея достаточный опыт работы в этой сфере, могут стать лишь подразделением публичных библиотек. Новый Модельный стандарт публичных библиотек вменяет им в функции обслуживание слепых пользователей. Это, в свою очередь, может негативным образом сказаться на качестве предоставляемых услуг, так как публичные библиотеки не обладают соответствующими возможностями, техническими и человеческими ресурсами. Актуальность измерения качества услуг специальных библиотек для слепых обусловлена их высокой значимостью как социального института с универсальными возможностями удовлетворения основных потребностей инвалидов по зрению. Результаты исследования позволяют говорить о высокой удовлетворенности посетителей специальных библиотек для слепых качеством оказания услуг, что является одним из главных критериев в оценке работы учреждений культуры подобного типа. В выводах указывается на необходимость совершенствования методики измерения качества оказания услуг специальными библиотеками для слепых и возможности для дальнейшего изучения этого вопроса.

Ключевые слова: качество оказания услуг, независимая оценка качества услуг, удовлетворенность качеством, специальные библиотеки для слепых, региональные исследования.

\section{Введение}

Рубеж XX-XXI вв. отмечен заметными переменами в обществе по отношению к людям с ограниченными возможностями здоровья. На разных уровнях им стало адресно уделяться внимание. Этот процесс формировался через целый ряд документов, принятых на уровне мирового сообщества, охватив отдельные страны миры, в том числе и Россию.

\section{Развитие международного права в отношении инвалидов}

В контексте существующих международных правовых документов выделяется несколько этапов развития концепции прав инвалидов.

Первый этап связан с принятием в 1948 г. Всеобщей декларации прав человека [4]. Здесь в статье 27 прямо указывается на равенство прав всех людей в отношении доступа к объектам культуры и искусства, в том числе к библиотечным фондам.

На следующем этапе, в Конвенции ООН о правах инвалидов от 2006 г., дается полное определение, кого следует относить к инвалидам [11]. Среди основных понятий, использующихся в документе, есть термин «универсальный дизайн», который подразумевает использование так называемых ассистивных устройств для разных групп инвалидов.

По классификации ВОЗ к ассистивным средствам относятся инвалидные коляски, вспомогательные средства передвижения, протезы, слуховые аппараты и другие устройства, в том числе компьютерное и программное обеспечение [2].

Конвенция о правах инвалидов вступила в силу 3 мая 2008 г., Российская Федерация подписала ее 24 сентября 2008 г., а 3 мая 2012 г. Президентом Российской Федерации был подписан Федеральный закон № 46-Ф3 «О ратификации Конвенции о правах инвалидов» [21]. В соответствии со статьей 15 Конституции Российской Федерации указанная Конвенция является составной частью правовой системы государства [12].

\section{Ситуация}

\section{со специальными библиотеками} для слепых в России в XXI веке

В России на рубеже XX-XXI вв. был принят целый ряд нормативных документов с целью организации системной поддержки людей с особыми потребностями [16; 19; 20; 22]. Доступ лиц с ограниченными возможностями здоровья к услугам организаций культуры, в том числе библиотекам, является обязательным условием и неотъемлемой формой полноценной социальной реабилитации.

Всего на территории России действуют 72 специальные библиотеки для слепых с 127 филиалами и 1148 библиотечными пунктами. Они обслуживают в среднем в год около 170,0 тыс. инвалидов по зрению. Государственные специальные библиотеки для слепых в форме бюджетных или казенных организаций являются наиболее доступными для 
лиц с ограниченными возможностями. Они оказывают государственные или муниципальные услуги, а также выполняют определенные работы и исполняют государственные или муниципальные функции.

Современное библиотековедение и библиотечная практика основываются на методологическом аппарате, выработанном на протяжении XX-XXI вв. отечественными и зарубежными учеными $[6 ; 9 ; 10 ; 14 ; 18 ; 23-26]$. Как указывает Г.П. Диянская [7], в основе современной парадигмы лежит принцип «равных возможностей», который предполагает, что каждый человек в любом библиотечно-информационном учреждении, независимо от расположения, имеет право получить доступ к необходимой информации или документам. На качество оказания этих услуг влияют многие факторы, в том числе существующие барьеры, начиная от физических и технологических и заканчивая финансовыми, организационными и другими. Ограничения доступа к услугам касаются в первую очередь людей с инвалидностью. То есть граждане не могут реализовать на практике свои права, подробно изложенные в международных и российских документах.

Однако это не единственное противоречие в реализации прав людей с ограниченными возможностями здоровья. В поле общественной дискуссии - вопрос о статуте специальных библиотек для слепых.

С одной стороны, популяризируется идея «интегрированного библиотечного обслуживания», которая находит свое отражение в «Модельном стандарте деятельности публичной библиотеки» от 2008 года [13]. Здесь отмечается, что для незрячих и слабовидящих пользователей библиотека обеспечивает доступ к информационным электронным средствам с помощью различных средств и технологий (программы экранного доступа, синтезаторы речи, конверторы и т. д.). Для любого пользователя библиотека должна предоставить полный спектр услуг и обеспечить удовлетворенность их качеством. С этой целью устанавливается «всеобщий стандарт обслуживания»максимально доступный фонд документов. На всех этапах предоставления услуг осуществляется оценка их качества и результативности, начиная от выявления потребностей посетителей, изучения спроса на услуги, их разработки, планирования, включая рекламу, до анализа удовлетворенности услугами библиотеки. Общую оценку составляют следующие характеристики библиотечных услуг: их соответствие спросу, содержательность и информативность; оперативность их выполнения; современные технологии их предоставления и исполнения; уникальность и общее количество услуг для инвалидов, которые могут быть самостоятельно дополнены библиотекой. В качестве эффективного инструмента управления качеством оказания услуг предлагается разработка комплекса внутренних требований и стандартов.

По мнению Н.И. Герасимовой [5], доступная среда для инвалидов по зрению может быть создана не только в специализированных библиотеках, но и в любой публичной библиотеке. Ограничения в данном вопросе касаются наличия тифлотехнических устройств, специальных изданий для незрячих пользователей, приспособленных зданий и отсутствия других ресурсов. Сотрудникам библиотеки необходима теоретическая и методическая поддержка в данной сфере.

Вопрос о включении специальных библиотек для слепых в общую библиотечную систему России должен быть еще проработан с учетом возможных негативных последствий (уменьшение финансирования, снижение уровня качества обслуживания слепых пользователей). Вопрос удовлетворенности сложившейся системой библиотечного обслуживания незрячих людей может включать в себя и такой аспект, как возможности включения специальных библиотек для слепых в качестве подразделения других библиотек.

Специальные библиотеки для слепых можно рассматривать как инновационные учреждения, поскольку в условиях технического прогресса библиотеки стремятся осваивать новые технологии, шире использовать информационные ресурсы, которые будут обеспечивать максимальное удовлетворение информационных потребностей читателей.

\section{Исследование качества оказания услуг специальными библиотеками для слепых}

Измерение удовлетворенности качеством услуг посетителей специальных биб- 
лиотек для слепых проводится во всех регионах РФ [17] с публичным обсуждением результатов [1].

Эмпирическая база исследования включает в себя результаты социологического опроса, проведенного среди посетителей Курской областной специальной библиотеки для слепых имени В.С. Алехина в сентябре - октябре 2016 г. в рамках проведения независимой оценки качества оказания услуг организациями культуры Курской области $(N=200)$ методике, разработанной Министерством культуры РФ. Опрос проводился в Курской областной специальной библиотеке для слепых, в пунктах выдачи при местных организациях ВОС и при межпоселенческих библиотеках Курской области. Для анализа вторичных данных использованы результаты социологического исследования, проведенного специальной библиотекой для слепых Республики Коми имени Луи Брайля в 2013 г., в котором изучалась удовлетворенность пользователей библиотечным, библиографическим и информационным обслуживанием $(N=50)$. Сбор эмпирических данных осуществлялся методом анкетирования.

Курская областная специальная библиотека для слепых имени В.С. Алехина работает в системе госзадания, то есть оказывает государственную услугу по библиотечному библиографическому и информационному обслуживанию пользователей библиотеки. В системе библиотеки работают 32 библиотечных пункта, которые обслуживают 2300 читателей. Фонд книг доступных форматов составляет 83353 экземпляров и включает в себя печатные издания, аудиовизуальные материалы, электронные материалы, рукодельные тактильные книги. Студия звукозаписи при библиотеке перевела в специальный формат и издала книги курских писателей В. Алехина, Е. Носова, К. Воробьева, Н. Шадрина и др. Библиотекой издаются звуковые журналы «Вестник Курского края» и «Будьте здоровы!». В библиотеке функционируют два клуба, ориентированных на работу с детьми и молодежью («Лучик» и «Оптимист») [15]. Библиотека проводит большую массовую работу с пользователями. На ее базе функционирует кружок любителей музыки - «Романсовая гостиная», театральный кружок «Данко», шко- ла православия «Святое слово» [3]. В библиотеке активно развивается такое направление, как «туротерапия», которое заключается в организации экскурсионных маршрутов по историческим местам для незрячих пользователей.

Опрос респондентов проводился по анкете, составленной из четырех тематических блоков.

В первый «Комфортность условий предоставления услуг и доступность их получения〉 входила оценка комфортности условий пребывания в библиотеке (наличие гардероба, чистоту помещений и другие необходимые вещи). Почти все опрошенные $(99,5 \%$ д) довольно высоко оценили этот показатель, отметив, что в библиотеке созданы «очень комфортные» и «вполне комфортные» условия пребывания. Это объясняется тем, что в специальных библиотеках создаются и поддерживаются максимально комфортные условия для работы и отдыха пользователей. Также здесь оценивалась доступность цены на оказываемые услуги, ее соответствие качеству. К дополнительным услугам Курской областной специальной библиотеки слепых относятся так называемые «сопутствующие услуги», предоставляемые пользователям библиотеки в строгом соответствии с Уставом организации. Так, $79 \%$ респондентов считают, что их стоимость полностью соответствует их качеству; $13 \%$ - отмечают, что стоимость дополнительных услуг не совсем соответствует их качеству; $8 \%$ - стоимость дополнительных услуг не соответствует их качеству. Кроме этого, здесь респондентам было предложено оценить транспортную и пешую доступности организации культуры. Подавляющее большинство (93 \%) считают, что «библиотека находится в доступном и удобном месте». Завершал этот блок вопрос об удобстве пользования электронными сервисами, представляемыми учреждением посетителям: $72 \%$ пользователей библиотеки отмечают, что им «очень удобно пользоваться электронными сервисами», предоставляемыми учреждениями; $22,5 \%$ считают, что им «достаточно удобно пользоваться электронными сервисами»; 5 \% пользователей отметили, что им «скорее удобно пользоваться электронными сервисами, чем нет». Высокая оценка удобства пользования электронными сервисами 
подтверждается тем, что в Курской областной специальной библиотеке для слепых имеется достаточно много записей в электронной библиотеке «говорящих» книг с криптозащитой. Посетители работают в сети Интернет, используя автоматизированные рабочие места, самостоятельно, с помощью русифицированной версии программы экранного доступа незрячих к персональному компьютеру JAWS for WINDOWS.

В составе библиотечного фонда имеются издания, размещенные на таких носителях, как: аудиокассеты, CD-ROM, флэш-карты. Активно ведется работа с сайтом библиотеки http://blindlibkursk.ru/, организованы официальные группы и виртуальные представительства библиотеки в социальных сетях: на социальном сервере Твиттер https://twitter.com/ blindry, Одноклассники. Также в информационное обслуживание пользователей внедрена новая услуга: on-line-информирование коллективных абонентов информирования. Использование программы TalkingBookLibrary и электронной библиотеки av3715.ru позволило оперативно выполнять индивидуальные заказы пользователей по записи книг на флэш-карты в защищенном цифровом формате.

Для более качественного оказания услуг в здании библиотеки созданы специализированные рабочие места для незрячих пользователей, есть специальные адаптированные технические средства для слепых, которые им помогают в прочтении/прослушивании книг. Также была начата работа по продвижению услуг библиотеки через сенсорный информационный киоск. Установка сенсорного монитора при входе в библиотеку - это новый шаг в новых возможностях обслуживания пользователей через дополнительные сервисы; обеспечение комфортного доступа к информации. Сенсорный киоск - это возможность продемонстрировать новые возможности специальных библиотек, и равные возможности их читателей. В настоящее время, воспользовавшись сенсорным монитором, читатели Курской областной специальной библиотеки для слепых могут узнать график работы библиотеки, познакомиться с ее структурой, прослушать новости, получить информацию об услугах, которые библиотека предлагает своим пользователям.
Во второй блок «Время ожидания предоставления услуги» входило два вопроса. Первый касался удобства графика работы организации культуры, и здесь большинство пользователей $(93,5$ \%) отмечают, что график работы библиотеки очень удобный. Это очень важно, так как формирование доступной среды для людей с ограниченными возможностями является приоритетным проектом в регионе. Сегодня в системе интегрированного библиотечного обслуживания инвалидов работают 32 библиотечных пункта, также успешно работают пункты выдачи при местных организациях ВОС, при межпоселенческих библиотеках Курской области. Что касается простоты и удобства электронного каталога, то, отвечая на этот вопрос, $75 \%$ опрошенных высоко оценили простоту/удобство электронного каталога библиотеки; 16 \% пользователей считают, что электронный каталог работает хорошо, а 4 \% - хотели, чтобы он работал лучше. В действительности электронный каталог Курской областной специальной библиотеки для слепых отражает все многообразие информационных ресурсов библиотеки и является одним их главных показателей информатизации библиотеки и качества ее работы. Электронный каталог позволяет пользователю найти требуемое количество изданий в электронном виде непосредственно в библиотеке, и он достаточно прост в использовании.

Третий блок состоял из одного вопроса, выявляющего уровень персонала учреждения культуры. В целом 98 \% оценивают персонал библиотеки как «очень доброжелательный, вежливый и компетентный персонал».

Четвертый блок «Удовлетворенность качеством оказания услуг» был составлен из вопроса об уровне этой удовлетворенности, на который 93,5 \% респондентов ответили, что «полностью удовлетворены качеством оказания услуг библиотекой» и вопроса о наличии информации о новых изданиях, что также имеет важное значение в этом показателе. Большинство пользователей $(66,5 \%)$ отметили, что информация о новых изданиях имеется. В свою очередь 33,5 \% пользователей отметили, что информации о новых изданиях нет и библиотеке необходимо регулярно и оперативно информировать незрячих пользователей о них различными способами, оперативно раз- 
мещать информацию на сайте библиотеки, различных группах в социальных сетях, на сенсорном информационном киоске.

Сравнивая эти показатели с данными исследований, проведенными по подобной методике в разных библиотеках для слепых на территории Российской Федерации, можно увидеть, что везде созданы достаточно комфортные условия предоставления услуг и доступность их получения [5].

\section{Выводы}

Таким образом, результаты исследований, проведенных в последние годы по разной методике в нескольких специальных библиотеках для слепых, выявляют высокий, а иногда и почти максимальный уровень удовлетворенности посетителей. Так, подавляющее большинство посетителей Курской областной специальной библиотеки слепых в целом по различным критериям оценки полностью удовлетворены качеством оказания услуг. Нисколько не подвергая сомнению ту высокую социальную позицию, которую занимают библиотеки в среде людей с ограниченными возможностями здоровья, нужно отметить следующее. Во-первых, высокие результаты опросов могут быть вызваны желанием посетителей библиотек получать как можно больше внимания со стороны всех заинтересованных организаций. Во-вторых, они могут свидетельствовать о несоответствии применяемых методов, так как зачастую они не адаптированы к данному вопросу. Например, упомянутые в статье показатели рассчитаны на все организации культуры без учета их типа и возможностей. Разработка методики расчета показателей для специальных учреждений, в том числе и библиотек, представляется перспективным направлением научного поиска. Это может способствовать получению объективной картины и формулированию более конкретных выводов, чем те, которые делаются, как правило, в формулировках рекомендаций.

\section{СПИСОК ЛИТЕРАТУРЫ}

1. Андриянова, Т. В. Сфера региональной культуры в показателях и оценках / Т. В. Андрияно- ва // Logos et Praxis. - 2017. - Vol. 16, № 3. - DOI: http: //doi.org/10.15688/lp.jvolsu.2017.3.11. - Электрон. текстовые дан. - Режим доступа: http://psst.jvolsu.com /index.php/ru/component/attachments/download/1115 (дата обращения: 05.03.2018). - Загл. с экрана.

2. Ассистивные устройства и технологии. Инвалидность и реабилитация. Всемирная организация здравоохранения. - Электрон. текстовые дан. Режим доступа: www.who.int/disabilities/technology/ $\mathrm{ru}$ (дата обращения: 12.03.18). - Загл. с экрана.

3. Беляева, Л. Н. Театральные постановки молодых инвалидов в центре «Данко» / Л. Н. Беляева // Социальная работа. - 2011. - № 5. - С. 44-45.

4. Всеобщая декларация прав человека. - Электрон. текстовые дан. - Режим доступа: www.un.org/ $\mathrm{ru} /$ documents/decl conv/declarations/declhr.shtml (дата обращения: $1 \overline{2} .03 .18$ ). - Загл. с экрана.

5. Герасимова, Н. И. Место и роль специальной библиотеки в организации досуга инвалидов по зрению / Н. И. Герасимова // IN SITU. - 2015. № 1. - C. 110-113.

6. Гришанина, В. А. Мир, овеянный «Крыльями надежды» / В. А. Гришанина // Библиотека. 2014. - № 3. - С. 50-52.

7. Диянская, Г. П. Принцип равных возможностей в тифлобиблиотековедении и библиотечном обслуживании инвалидов по зрению : дис. ... д-ра пед. наук : 05.25.03 / Диянская Галина Петровна. М., 1998. $-343 \mathrm{c}$.

8. Информация о деятельности Специальной библиотеки для слепых республики Коми имени Луи Брайля за 2013 год. - Электрон. текстовые дан. Режим доступа: http://www.starblind.komisbs.ru/ content/198/отчет\%20на\%20сайт.docx (дата обращения: 05.03.2018). - Загл. с экрана.

9. Кан, А. М. Социальная интеграция инвалидов / А. М. Кан // Социальная политика и социология. -2008 . - № 3. - С. 138-147.

10. Кирилюк, О. М. Социологический анализ системы реабилитации инвалидов (на материалах исследований в г. Санкт-Петербурге) / О. М. Кирилюк // Отечественный журнал социальной работы. -2008 . - № 4. - C. 48-55.

11. Конвенция ООН о правах инвалидов. - Электрон. текстовые дан. - Режим доступа: http: //ombudsmanspb.ru/files/files/OON_02_site.pdf(дата обращения: 12.03.18). - Загл. с экрана.

12. Конституция Российской Федерации. Электрон. текстовые дан. - Режим доступа: http: //www.constitution.ru/ (дата обращения: 05.03.18).Загл. с экрана.

13. Модельный стандарт деятельности публичной библиотеки. Новая редакция. - Электрон. текстовые дан. - Режим доступа: http://www.rba.ru/ content/about/doc/mod_publ.php (дата обращения: 05.03.2018). - Загл. с экрана. 
14. Наберушкина, Э. К. Инвалидность и право на независимую жизнь / Э. К. Наберушкина // Вестник Московского университета. Серия 18, Социология и политология. - 2009. - № 4. - С. 128-137.

15. Областное казенное учреждение культуры «Курская областная специальная библиотека для слепых имени В.С. Алехина». - Электрон. текстовые дан. - Режим доступа: http://www.blindlibkursk.ru/ (дата обращения: 05.03.2018). - Загл. с экрана.

16. Постановление Правительства РФ от 01.12.2015 № 1297 (ред. от 30.03.2018) «Об утверждении государственной программы Российской Федерации “Доступная среда” на 2011-2020 годы». Электрон. текстовые дан. - Режим доступа: http: //pravo.gov.ru/proxy/ips/?docbody=\&nd=102383642 (дата обращения: 05.03.2018). - Загл. с экрана.

17. Приказ Министерства культуры Российской Федерации от 25.02.2015 № 288 «Об утверждении показателей, характеризующих общие критерии оценки качества оказания услуг организациями культуры» (с изм. от 07.08.2015 № 2168). - Электрон. текстовые дан. - Режим доступа: http://www. rosmintrud.ru/docs/mintrud/analytics/66 (дата обращения: 01.03.2018). - Загл. с экрана.

18. Сухих, В. Г. Региональные модели реабилитации инвалидов / В. Г. Сухих // Социологические исследования. - 2011. - № 8. - С. 98-101.

19. Указ Президента РФ от 27.07.1992 № 802 «О научном и информационном обеспечении проблем инвалидности и инвалидов». - Электрон. текстовые дан. - Режим доступа: http://www.kremlin.ru/ acts/bank/1731 (дата обращения: 05.09.2018). - Загл. с экрана.

20. Федеральный закон «О социальной защите инвалидов в Российской Федерации» от 24.11.1995 № 181-Ф3 (последняя редакция). - Электрон. текстовые дан. - Режим доступа: http://www.consultant. ru/document/cons_doc_LAW_8559/ (дата обращения: 05.03.2018). - Загл. с экрана.

21. Федеральный закон от 01.12.2014 № 419-Ф3 «О внесении изменений в отдельные законодательные акты Российской Федерации по вопросам социальной защиты инвалидов в связи с ратификацией Конвенции о правах инвалидов». - Электрон. текстовые дан. - Режим доступа: https://giod. consultant.ru/page.aspx?3664645 (дата обращения: 05.03.2018). - Загл. с экрана.

22. Федеральный закон от 03.05.2012 № 46-Ф3 «О ратификации Конвенции о правах инвалидов». Электрон. текстовые дан. - Режим доступа: http: //legalacts.ru/doc/federalnyi-zakon-ot-03052012-n-46fz-o/ (дата обращения: 05.03.2018). - Загл. с экрана.

23. Шапошников, А. Е. Место массовой библиотеки в системе обслуживания инвалидов / А. Е. Шапошников // Библиотековедение. - 1995. № 2. - C. 52-57.
24. Massis, B. E. The Practical Library Manager / B. E. Massis. - N. Y. : Routledge, 2012. - 140 p.

25. Massis, B. E. The Practical Library Trainer / B. E. Massis. - L. : Haworth Press, 2004. - 122 p.

26. Massis, B. E. International Loan of Alternative Format Materials: a Balanced Sourcebook / eds.: B. E. Massis, W. Vitzansky. - L. : Haworth Press, 1992. $-196 \mathrm{p}$.

\section{REFERENCES}

1. Andriyanova T.V. Sfera regionalnoy kultury v pokazatelyakh i otsenkakh [The Sphere of Regional Culture in Indicators and Estimates]. Logos et Praxis, 2017, vol. 16, no. 3. URL: http://psst.jvolsu. com/ index.php/ru/archive-ru/228-logos-et-praxis-2017-tom16-3/ (accessed 5 March 2018).

2. Assistivnye ustroystva $i$ tekhnologii. Invalidnost i reabilitatsiya. Vsemirnaya organizatsiya zdravookhraneniya [Assistive Devices and Technologies. Disability and Rehabilitation. World Health Organization]. URL: http:// www.who.int/ disabilities/technology/ru/ (accessed 5 March 2018).

3. Belyaeva L.N. Teatralnye postanovki molodykh invalidov v tsentre «Danko» [Theatrical Performances ofYoung Disabled People in the Social Center Danko]. Sotsialnaya rabota, 2011, no. 5, pp. 44-45.

4. Vseobshchaya deklaratsiya prav cheloveka [Universal Declaration of Human Rights]. URL: http:/ /un.org/ru/documents/decl_conv/declarations/ declhr.shtml (accessed 5 March 2018).

5. Gerasimova N.I. Mesto i rol spetsialnoy biblioteki v organizatsii dosuga invalidov po zreniyu [Place and Role of the Special Library in the Organization of Leisure for the Visually Impaired]. IN SITU, 2015, no. 1, pp. 110-113.

6. Grishanina V.A. Mir, oveyannyy «Krylyami nadezhdy" [The World Covered with "Wings of Hope”]. Biblioteka, 2014, no. 3, pp. 50-52.

7. Diyanskaya G.P. Printsip ravnykh vozmozhnostey $v$ tiflobibliotekovedenii i bibliotechnom obsluzhivanii invalidov po zreniyu: dis. ... d-ra ped. nauk [The Principle of Equal Opportunities in Typhlo-Library Studies and Library Service for the Visually Impaired. Dr. ped. sci. diss.]. Moscow, 1998. 343 p.

8. Informatsiya o deyatelnosti Spetsialnoy biblioteki dlya slepykh respubliki Komi imeni Lui Braylya za 2013 god [Information on the Activities of Special Library for the Blind of the Komi Republic Louis Braille for 2013]. URL: http://www.starblind. komisbs.ru/content/198/отчет\%20на \%20сайт.docx (accessed 5 March 2018).

9. Kan A.M. Sotsialnaya integratsiya invalidov [Social Integration of Disabled People]. Sotsialnaya politika i sotsiologiya, 2008, no. 3, pp. 138-147. 
10. Kirilyuk O.M. Sotsiologicheskiy analiz sistemy reabilitatsii invalidov (na materialakh issledovaniy v g. Sankt-Peterburge) [Sociological Analysis of the Rehabilitation System for Disabled People (Based on Research in St. Petersburg)]. Otechestvennyy zhurnal sotsialnoy raboty, 2008, no. 4, pp. 48-55.

11. Konventsiya OON o pravakh invalidov [The UN Convention on the Rights of Disabled People]. URL: http://un.org/ru/documents/decl_conv/ conventions/disabled.shtml (accessed 5 March 2018).

12. Konstitutsiya Rossiyskoy Federatsii [The Constitution of the Russian Federation]. URL: http: //www.constitution.ru/ (accessed 5 March 2018).

13. Modelnyy standart deyatelnosti publichnoy biblioteki. Novaya redaktsiya [Model Standard of Public Library Functioning. New Edition]. URL: http:/ /rba.ru/content/about/doc/mod_publ.php (accessed 5 March 2018).

14. Naberushkina E.K. Invalidnost i pravo na nezavisimuyu zhizn [Disability and the Right to an Independent Life]. Vestnik Moskovskogo universiteta. Seriya 18, Sotsiologiya i politologiya, 2009, no. 4, pp. 128-137.

15. Oblastnoe kazennoe uchrezhdenie kultury «Kurskaya oblastnaya spetsialnaya biblioteka dlya slepykh imeni V.S. Alekhina» [Regional State Institution of Culture "Kursk Regional Special Library for the Blind named after V. S. Alekhin"]. URL: http: // blindlibkursk.ru/ (accessed 5 March 2018).

16. Postanovlenie Pravitelstva RF ot 01.12.2015 № 1297 (red. ot 30.03.2018) «Ob utverzhdenii gosudarstvennoy programmy Rossiyskoy Federatsii "Dostupnaya sreda" na 2011-2020 gody» [Decree of the Government of the Russian Federation of 1 December 2015 No. 1297 (ed. of 30 March 2018) “On Approval of the State Program of the Russian Federation 'Affordable Environment for 2011-2020"']. URL: http:// pravo.gov.ru/proxy/ips/?docbody=\&nd= 102383642 (accessed 5 March 2018).

17. Prikaz Ministerstva kultury Rossiyskoy Federatsii ot 25.02.2015 № $288 « O b$ utverzhdenii pokazateley, kharakterizuyushchikh obshchie kriterii otsenki kachestva okazaniya uslug organizatsiyami kultury» (s izm. ot 07.08.2015 № 2168) [Order of the Ministry of Culture of the Russian Federation of 25 February 2015 No. 288 “On Approval of Indicators of the General Criteria for Evaluation of the Quality of Services Provided by Cultural Organizations" (with amendment of 7 August
2015 No. 2168)]. URL: http://www.rosmintrud.ru/docs/ mintrud/analytics/66 (accessed 5 March 2018).

18. Sukhikh V.G. Regionalnye modeli reabilitatsii invalidov [Regional Models of Rehabilitation of Disabled People]. Sotsiologicheskie issledovaniya, 2011, no. 8, pp. 98-101.

19. Ukaz Prezidenta RF ot 27.07.1992 № 802 «O nauchnom i informatsionnom obespechenii problem invalidnosti i invalidov»" [Decree of the President of the Russian Federation of 27 July 1992 No. 802 "About Scientific and Information Provision of Problems of Disability and Disabled People"]. URL: http://www.kremlin.ru/acts/bank/1731 (accessed 5 March 2018).

20. Federalnyy zakon «O sotsialnoy zashchite invalidov v Rossiyskoy Federatsii» ot 24.11.1995 № 181-FZ (poslednyaya redaktsiya) [Federal Law "On Social Protection of Disabled People in the Russian Federation" of 24 November 1995 No. 181-FZ (Latest Edition)]. URL: http://www.consultant.ru/document/ cons_doc_LAW_8559 (accessed 1 March 2018).

21. Federalnyy zakon ot 01.12.2014 № 419-FZ "O vnesenii izmeneniy $v$ otdelnye zakonodatelnye akty Rossiyskoy Federatsii po voprosam sotsialnoy zashchity invalidov v svyazi s ratifikatsiey Konventsii o pravakh invalidov» [Federal Law of 1 December 2014 No. 419-FZ “On Amending Certain Legislative Acts of the Russian Federation on Social Protection of Persons with Disabilities in Connection with Ratification of the Convention on the Rights of Persons with Disabilities"]. URL: https://giod.consultant.ru/ page.aspx?3664645 (accessed 5 March 2018).

22. Federalnyy zakon ot 03.05.2012 № 46-FZ "O ratifikatsii Konventsii o pravakh invalidov» [Federal Law of 3 May 2012 No. 46-FZ “On Ratification of the Convention on the Rights of Persons with Disabilities"]. URL: http://legalacts.ru/doc/federalnyizakon-ot-03052012-n-46-fz-o/ (accessed 5 March 2018).

23. Shaposhnikov A.E. Mesto massovoy biblioteki v sisteme obsluzhivaniya invalidov [Place of the Mass Library in the System of Services for Disabled People]. Bibliotekovedenie, 1995, no. 2, pp. 52-57.

24. Massis B.E. The Practical Library Manager. New York, Routledge, 2012. 140 p.

25. Massis B.E. The Practical Library Trainer. London, Haworth Press,2004.122 p.

26. Massis B.E., Vitzansky W., eds. International Loan of Alternative Format Materials: a Balanced Sourcebook. London, Haworth Press, 1992. 196 p. 
T.B. Андриянова. Качество оказания услуг специальными библиотеками для слепых

\section{Information about the Author}

Tatyana V. Andriyanova, Candidate of Sciences (Sociology), Associate Professor of Department of Sociology, Kursk State University, Radishcheva St., 29, 305004 Kursk, Russian Federation, andriyanova.tv@gmail.com.

\section{Информация об авторе}

Татьяна Владимировна Андриянова, кандидат социологических наук, доцент кафедры социологии, Курский государственный университет, ул. Радищева, 29, 305004 г. Курск, Российская Федерация, andriyanova.tv@gmail.com. 